Faculdade de Motricidade Humana, Universidade de Lisboa

https://doi.org/10.5628/rpcd.16.S1.12

\section{A criação dos Institutos \\ Superiores de Educação Física \\ (Dec. Lei 675/75)}

passos evolutivos e passei pelos principais eventos que transformaram e permitiram criar as condições de entrada da Educação Física e Desporto na Universidade. Estou muito feliz por isso e por vos trazer hoje alguns fatos que são desconhecidos para muitos de vós no decurso deste processo inigualável no Ensino Superior Universitário Português.

\section{CRIAÇÃO DOS INSTITUTOS}

\section{SUPERIORES DE EDUCACÃO FÍSICA}

Conferência proferida na cerimónia evocativa da criação do ISEF do Porto e da sua integração na Universidade do Porto. Integrada na sessão solene

Hoje comemoramos uma data com grande significado histórico, considerando as mudanças efetuadas no estatuto dado à nossa área profissional e principalmente às oportunidades criadas para a sua integração plena na cultura académica e universitária. Vários de abertura do ano lectivo.

Em primeiro lugar gostaria de agradecer o amável convite feito pelo Diretor da Faculdade de Desporto da Universidade do Porto, Professor Doutor Jorge Bento, para realizar a oração de sapiência nesta sessão solene do dia desta Faculdade. Seria natural que esta comunicação fosse realizada sobre um tema original e aprofundada de forma filosófica ou científica e com a nobreza intelectual que uma sessão deste tipo exige. Não escolhi esse caminho. Optei por vos contar alguns episódios mais significativos da história da criação dos Institutos Superiores de Educação Física, fato que marcou os nossos destinos institucionais e profissionais e que comemoramos precisamente no dia de hoje 40 anos, com a publicação do Decreto-Lei 675/75 de 3 de Dezembro desse mesmo ano. É uma pequena e grande estória que está por contar. Neste sentido, é uma grande honra para mim, participar neste desafio em recordar os fatos que se passaram em tempos politicamente e institucionalmente difíceis, mas decisivos no rumo que foi dado na emancipação universitária da nossa área de conhecimento. As pessoas e as instituições devem preservar a sua memória. A memória dá sentido de identidade. 0 passado não deve ser esquecido. Tive a oportunidade e o privilégio de ter frequentado como estudante a EIEFL (1967/69), e o INEF (1970/75), e como professor o ISEF (1976/1988) e a FMH (1989/2015). Foram 48 anos de aprendizagem e vivência histórica que não poderei nunca esquecer. Passámos tempos de grande complexidade, conturbados e felizes mas a avaliação final é deveras positiva. Do chão e do quase nada construímos uma área de saber e de intervenção que hoje tem visibilidade, identidade própria e é reconhecida Nacional e Internacionalmente. Participei em todos os acontecimentos se passaram antes, durante e depois da publicação do referido decreto e que merecem ser identificados e descritos com toda a atenção de um ponto de vista histórico. Como podem perceber, foi um processo difícil e que implicou uma grande participação de todos os intervenientes num contexto historicamente relevante para Portugal e para a implementação da democracia plena, num país arrastado por 50 anos de miserabilismo cívico, politico, social, laboral, educativo e científico.

A situação da formação de profissionais de Educação Física antes do dia 25 de Abril de 1974 era a seguinte:

1. A existência do Instituto Nacional de Educação Física (INEF), e conhecido como uma instituição especializada de ensino superior não universitário destinada à formação de docentes de educação física, criada pelo Decreto-Lei n.ํㅜ 30 279, de 23 de Janeiro de 1940 no âmbito da reforma Carneiro Pacheco, então Ministro da Educação Nacional do regime do Estado Novo, tendo por objetivo uma profunda reestruturação do sistema educativo português. 0 INEF destinava-se a "estimular e orientar, dentro da missão cooperadora do Estado com a família, e no plano da educação integral estabelecido pela Constituição, o revigoramento físico da população portuguesa". Estava previsto que o curso de habilitação de professor de educação física era constituído por "disciplinas que assegurassem, a par da preparação social, a formação bio - pedagógica e técnica segundo os métodos de "Ling", tendo em vista as condições mesológicas do nosso País e a capacidade fisiopsicológica da raça". 0 diploma permitia também a criação de institutos e centros formativos de agentes de ensino de educação física noutras cidades, em especial Coimbra e Porto, com a colaboração das autarquias locais, em tudo sujeitos à jurisdição e orientação técnica do Ministério da Educação Nacional, através do INEF. Era ainda referido que o ensino era realizado em regime de separação de sexos e numa cooperação efetiva com a Mocidade Portuguesa. 0 primeiro subdiretor do INEF foi António Leal de Oliveira, personalidade que influenciou a sua criação e uma das figuras mais influentes na discussão metodológica que em meados 
do século XX dividiu em Portugal os defensores da educação física e do desporto. Esteve envolvido, desde o início da década de 1930, com muitas outras figuras da educação física e da pedagogia, na realização de um curso superior de educação física concebido nos moldes do Instituto de Estocolmo, que funcionou na Sociedade de Geografia de Lisboa de 1930 a 1940 tendo por base o método de Ling (a famosa ginástica sueca). A instituição INEF fo instalada em edifício especificamente concebido e construído para o efeito, junto ao Estádio Nacional no vale do Jamor, concelho de Oeiras. As mesmas instalações ainda são utilizadas pela Faculdade de Motricidade Humana, instituição que sucedeu ao Instituto Nacional de Educação Física (1940/1975) e Instituto Superior de Educação Física (1975/1989);

2. A existência das Escolas de Instrutores de Educação Física de Lisboa e Porto, criadas pelo Decreto-Lei 49233 de 11/09/69 na sequência do Decreto 46912, de 19 de Março de 1966, que definiu as funções dos instrutores de educação física, institucionalizando, assim, os respetivos cursos que foram sendo regidos nas duas cidades desde 1961 em Lisboa e desde 1964 na cidade do Porto. Eram estabelecimentos de ensino público, de grau médio, que estavam na dependência da Direcção-Geral da Educação Física, Desportos e Saúde Escolar. Os diplomados por qualquer das referidas Escolas tinham o direito ao título de instrutores de educação física e ficavam habilitados a ministrar educação física, sob a orientação de diplomados com o curso de professores do Instituto Nacional de Educação Física, em estabelecimentos de ensino público ou particular ou ainda em organismos onde se praticavam atividades gimnodesportivas. Este curso de instrutores de educação física tinha a duração de dois anos e eram admitidos a frequentar o curso os indivíduos de qualquer dos sexos habilitados com o 2.. ciclo dos liceus ou habilitações equivalentes para este fim especial e aprovados em exame de aptidão. Através da portaria 655/70 do Ministério do Ultramar, foram também mandadas criar as Escolas de Instrutores de Educação Física de Lourenço Marques em Moçambique e de Luanda em Angola na sequência do mesmo Decreto-Lei. Devo ainda acrescentar, que chegou a ser pensada a abertura de uma Escola de Instrutores de Educação Física em Coimbra com a tutela da Direção Geral dos Desportos e com um grande entusiasmo do Dr.ํ Mendes Silva, então Presidente da Camara Municipal e grande entusiasta do Desporto.

Importa referir que estas escolas foram pioneiras na formação de professores em Portugal. Apesar de se viver num regime ditatorial, e com grande influência do pensamento médico e militar, a existência da educação física e desporto no contexto educativo, desportivo e militar atingiu um grande mérito e desenvolvimento a partir de profissionais muito competentes e reconhecidos socialmente. A disciplina de educação física na escola e seus respetivos professores eram muito acarinhados pelos alunos, assim como para os atletas no trabalho realizado nos clubes desportivos e em muitas modalidades desportivas.
O corpo docente no INEF e das EEF de Lisboa e Porto foi-se renovando e emancipando a velhos paradigmas, implementando novas metodologias de formação dos seus profissionais, não obstante existir uma vigilância apertada do regime a conceções novas sobre a fundamentação teórica e prática da educação física e desporto. Recordo como aspetos decisivos nesta mudança a criação da AIESEP e a FIEP que nos permitiu alargar os contatos pedagógicos e científicos a nível internacional e o aparecimento de docentes nestas escolas com formação em educação física e desporto. Neste âmbito, merecem ser destacados entre muitos outros acontecimentos, cinco aspetos que considero terem sido muito importantes para as mudanças operadas na educação física e desporto nestas escolas de formação:

1. O papel revolucionário desempenhado pelo saudoso professor José Maria Noronha Feio. Apenas com 19 anos, é na cidade do Porto que revela a sua tendência como animador cultural, presidindo à Direção do Círculo de Cultura do Porto e lecionando na Escola de Teatro do Círculo de Cultura Teatral do Porto. A sua dedicação e exemplo levaram-no no ano de 1963/68 a Director do então Instituto Nacional de Educação Física (INEF), cargo pela primeira vez desempenhado por um profissional de Educação Física. No curto período de 4 anos provocou modificações fundamentais na escola, através da realização sistemática de jornadas de divulgação por todo o país e também em África e no Brasil. No interior da escola, para além de uma democratização das relações, introduziu um sentimento de autoconfiança e segurança profissional, procurando abri-la a todas as atividades culturais (conferências, debates, concertos, exposições, viagens coletivas, criação de grupos representativos, etc.) e fazê-la sair dos seus estreitos muros para se projetar na sociedade e no País. Simultaneamente, traduziu e editou a obra de "J. Dumazedier" que veio influenciar significativamente a visão a que estava reduzida a atividade desportiva de então e promovendo pela primeira vez as relações Luso Brasileiras na nossa área profissional.

2. 0 impacto existente em Portugal do movimento cultural e político de Maio 68 em França quanto à introdução de um pensamento renovado nas universidades e movimentos de estudantes e em especial na educação física e deporto. A reflexão e o debate passaram a fazer parte do quotidiano dos estudantes, que com maior poder crítico, permitiu introduzir novos conceitos e referências teóricas e práticas. A introdução de literatura francesa nas áreas da pedagogia, história, antropologia física e cultural, psicologia evolutiva, biologia, psicanálise, filosofia, sociologia e política, alteraram definitivamente os hábitos de leitura dos estudantes e a conceção curricular da formação nas instituições existentes na época de educação física e desporto. 
3. A influência que vários periódicos tiveram na nossa formação e que chegavam a Portugal, com novidades relacionadas com a produção científica e pedagógica em educação física e desporto, como eram os casos da revista "Stadium" (Argentina), dos documentos realizados pelo Centro de documentação do INEF de Madrid com tradução de textos dos países de leste e com a liderança de José Maria Cagigal, da revista francesa "Education Physique et Sport" e de alguns livros que entretanto eram permitidos ser publicados e não censurados pelo regime vigente na época. É um excelente exemplo a publicação original em toda a Europa da obra do professor José Esteves (infelizmente falecido há cerca quinze dias atrás) publicada no final dos anos sessenta e intitulada "Desporto e Estruturas Sociais". Publicou no ano de 1975 um outro livro original intitulado "Racismo e Desporto".

4. 0 sucesso da instalação da Universidade de Lourenço Marques sob a direção de Veiga Simão e do projeto da Escola de Instrutores de Educação Física entre 1969 e 1973 com a suprema direção do Professor Noronha Feio, então Presidente do Conselho Provincial de Educação Física. Recordamos a publicação da revista "Educação e Movimento" e a formação de um excelente grupo de docentes entre os quais destaco, os Professores Hermínio Barreto, Teotónio Lima, Arcelino Mirandela da Costa, José Vilela, Carlos Abreu e João Boaventura.

5. $O$ regresso desta equipa a Portugal em 1973, que permite a Veiga Simão como ministro do governo de Marcelo Caetano iniciar a reforma do Sistema Educativo como Ministro da Educação e Ciência, e ao Professor Noronha Feio empossado como Diretor da Direção Geral dos Desportos, iniciar uma restruturação dos serviços, promovendo várias mudanças quanto ao desporto escolar e desporto federado. Recordo com saudade a minha colaboração ao integrar o Gabinete de Estudos de Investigação, nas instalações da Infante Santo, em conjunto com os professores António Paula Brito, Tanagra Medeiros, Manuel Brito, Mesquita Guimarães, Graça Esteves, e a publicação de vários documentos de divulgação de temas relacionados com a educação física e desporto e em colaboração com o Professor João Boaventura responsável pelo Centro de Documentação da respetiva Direção Geral.

OS ACONTECIMENTOS APÓS A REVOLUÇÃO DE ABRIL E PREPARAÇÃO DO DECRETO -LEI 675/75 Foi com muita emoção que o 25 de abril chegou e foi festejado pelos cidadãos portugueses. A luta política dos estudantes, trabalhadores e militares tinha finalmente resultado Este processo de democratização da sociedade portuguesa não foi um processo fácil como todos sabemos. As relações entre estudantes e docentes entraram em rutura e entrou-se num processo de negociação difícil quanto ao futuro. 0 INEF foi encerrado pelos estudantes e suspensas todas as atividades docentes no dia 29 de Maio de 1974, devido ao fato do corpo de docentes não ter indicado dois dos seus membros para integrarem uma Comissão Diretiva Provisória, entretanto criada em reunião geral de estudantes e trabalhadores. Estava em causa o saneamento de 7 professores aos quais foi requerida a demissão, e dentro destes o seu diretor. Esta situação prolongou-se por vários meses e com negociações com o Ministério de Educação e Cultura e até com a Junta de Salvação Nacional. Várias reuniões de Assembleia Geral de Alunos e de Escola foram realizadas tendo sido tomadas várias decisões sobre o funcionamento da escola. Realizaram-se vários debates com reconhecidos especialistas na área de educação física e desporto, relacionados com o estatuto profissional e as estratégias que deveriam ser seguidas para a promoção e dignificação da sua formação universitária. Os órgãos de comunicação social deram enorme destaque ao que se estava a passar na Cruz Quebrada e em outras instituições universitárias a propósito da luta estudantil. Porque os docentes estavam impedidos de entrar no INEF, foram realizadas várias reuniões no Centro de Estágio de Desportistas (espaço neutro) entre estudantes e docentes com a mediação do Professor Noronha Feio entretanto indicado pelo Ministério para tentar resolver o conflito. Os posicionamentos políticos muito diferenciados acentuaram-se e ao mesmo tempo também era necessário resolver a vida académica dos estudantes. Foi um período de grande intensidade de reflexão pedagógica, política e profissional. A vida política em Portugal vivia também momentos de grande agitação. As posições evoluíram e convergiram no bom sentido com uma posição muito interveniente do Ministério de Educação sobre a resolução do problema ao criar uma Comissão Instaladora dos Institutos Superiores de Educação Física por despacho de 2 de junho de 1974.

A CRIAÇÃO DA COMISSÃO INSTALADORA

A Comissão Instaladora dos Institutos Superiores de Educação Física toma posse no Ministério de Educação e Cultura (despacho anterior de António Espanha como Secretário de Estado do Ensino Superior) e inicia a sua atividade no dia 6 de Novembro de 1974 que é concluída em 10 de Julho de 1975. Era constituída pelos seguintes membros:

\section{António Paula Brito, nomeado como Presidente}

2. Olímpio Coelho como representante dos professores do INEF 3. Jorge Crespo como representante da EIEFL

4. José Manuel Constantino como representante dos alunos do INEF

5. Fátima Inácio como representante dos alunos ada EIEFL

6. José Augusto Santos como representante dos alunos da EIEFP

Deve notar-se a ausência de um representante dos professores da EIEFP. As razões de dificuldade de representação, deve-se a algumas divergências compreensíveis quanto ao fecho da escola e a continuidade dos alunos e do corpo docente. No entanto, ao consultar as atas da referida Comissão Instaladora, verifica-se de forma esporádica a presença neste grupo de 
trabalho dos Professores Miguel Graça Moura e Josef Wilson. Temos também a informação do grande empenhamento do então reitor da Universidade do Porto, Prof. Doutor José Sena no processo de criação do Instituto Superior de Educação Física do Porto, mostrando grande disponibilidade de colaboração em várias reuniões realizadas com a Comissão Instaladora.

A missão da Comissão Instaladora era complexa e num contexto político cheio de incertezas. 0 objetivo principal centrava-se em criar as condições adequadas de transição das escolas de Educação Física existentes em Lisboa e no Porto e a sua integração na Universidade. Da leitura atenta do relatório pode resumir-se em breves itens a sua atividade:

1. Dar seguimento a assuntos administrativos, pedagógicos e financeiros das escolas;

2. Dar solução à conclusão dos cursos existentes do ano letivo de 1973/74, preparação de estágios pedagógicos dos estudantes do 3 o ano do INEF e dos cursos ainda existentes nas EIEF

3. Preparar e realizar as avaliações das disciplinas referentes aos diversos cursos;

4. Gerir a existência de uma turma do curso de educação física de militares no INEF;

5. Realizar contatos e definir processos de negociação com diversas instituições relacionadas com a Educação Física e Desporto em Portugal;

6. Tratar com a Direção Geral do Ensino Superior do Ministério da Educação e Investigação Científica da preparação de legislação e decisões referentes ao processo de transição;

7. Preparar a Lei Orgânica dos futuros Institutos Superiores de Educação Física e reflexão das respetivas propostas com estudantes, trabalhadores, professores e Ministério da Educação e Investigação Científica;

8. Preparar as eleições para os órgãos de gestão e abertura de concursos de assistentes para os futuros Institutos Superiores de Educação Física do Porto e Lisboa;

9. Preparação de propostas de modelos curriculares para os futuros cursos de educação física dos Institutos Superiores de Educação Física do Porto e Lisboa.

Apesar de todos os constrangimentos porque passou o trabalho desta Comissão Instaladora, o balanço foi decisivo para a integração da Educação Física e Desporto na Universidade. A transição foi realizada sem grandes sobressaltos e a publicação da lei orgânica dos Institutos Superiores de Educação Física e Desporto de Lisboa e Porto viria a concretizar-se com sucesso.

A PUBLICAÇÃO DO DECRETO-LEI 675/75

Não posso deixar de referir um acontecimento especial e decisivo na preparação do Decreto-Lei 675/75, passados que estão quarenta anos após a sua publicação. No dia 26 de Novembro de 1975, um dia depois do famoso dia 25 de Novembro que marcou a turbulência porque passou a implementação do processo democrático em Portugal, teve lugar no Ministério da Educação e Cultura (MEC) uma reunião de trabalho para se tomar a decisão final da preparação e publicação do referido decreto-lei. Nesta reunião estiveram presentes o Major Vitor Alves (Ministro da Educação e Cultura), António Brotas (Secretário de Estado do Ensino Superior), Silva Graça (Secretário de Estado do Ensino Secundário), um jurista do Ministério cujo nome não conseguimos apurar, José Maria Noronha Feio (Inspetor do Ministério da Educação e Cultura); Alfredo Melo Carvalho (Diretor Geral dos Desportos), António Paula Brito (Presidente da Comissão Instaladora dos ISEFS), Carlos Abreu, Pedro Sarmento e Francisco Madeira pertencentes a uma Comissão Representante do curso de instrutores de Educação Física e João Jacinto e Manuela Miranda como representantes dos estudantes do Instituto Nacional de Educação Física. Esta famosa reunião teve início pelas 22 horas e terminou cerca das cinco horas da manhã do dia 27 de Novembro. Esta reunião histórica foi polémica e conturbada, considerando o debate de questões fundamentais do conteúdo jurídico do decreto-lei, em especial o número de anos de curso, o modo de efetuar a extinção do INEF e Escolas de Instrutores de Educação Física, a integração na universidade e o modelo de transição dos alunos existentes para o novo modelo de funcionamento dos cursos dos Institutos Superiores de Educação Física. As intervenções assertivas do Professor Noronha Feio e a notável capacidade de moderação do Major Vitor Alves (grande amigo da Educação Física e Desporto), parecem ter sido decisivas na decisão de promulgar o Decreto - Lei $675 / 75$ que viria a acontecer no dia 3 de dezembro de 1975. Passados trinta e cinco anos de expetativa e luta constante da Educação Física e Desporto poder ser considerada uma área de estudo e intervenção com legítima integração no Ensino Superior Universitário, foram tomadas importantes decisões nessa noite, que permitiram uma evolução notável da nossa área de conhecimento em termos institucionais e profissionais nas últimas quatro décadas. Pudemos apurar que foram diversificadas as contribuições de várias personalidades na elaboração do decreto-lei, destacando de entre muitas as de José Esteves, Carlos Abreu, Noronha Feio, Melo Carvalho e os membros da Comissão Instaladora dos ISEF'S com destaque para Jorge Crespo, António Paula Brito e José Manuel Constantino.

Através da publicação do Decreto-Lei n. $9675 / 75$ no dia 3 de Dezembro, foram criados o Instituto Superior de Educação Física de Lisboa e o Instituto Superior de Educação Física do Porto, e extinto o Instituto Nacional de Educação Física, a Escola de Instrutores de Educação Física de Lisboa e a Escola de Instrutores de Educação Física do Porto. 0 importante decreto é aprovado em Conselho de Ministros, assinado pelo General José Pinheiro Azevedo (Primeiro Ministro), Major Vitor Alves (Ministro de Educação e Cultura), Francisco Salgado Zenha, Vasco Leote Almeida Costa, e promulgado pelo General Francisco da Costa Gomes (Presidente da República). 
Convém recordar o preâmbulo do referido decreto-lei pelo significado que atribui à sua publicação: A preparação de especialistas em educação física
vem-se processando no Instituto Nacional de Educacão Física e nas Escolas de Instrutores de Educação Fisica de Lisboa e do Porto. O primeiro, embora de nivel superior, não se en-
contra ligado a nenhuma Universidade. As segundas são escolas que foram criadas para preparar docente' da disciplina de Educação Fisica, embora nunca se tivesse definido com justiça o estatuto profissional dos respectivos diplomados.

Acontece, porém, que, por estranha aberração, os diplomados por estas escolas oficiais estavam impedidos de fazer o esstágio pedagógico e de concorre para lugares do quadro das escolas preparatórias ou dos estabelecimentos de ensino secundário. Por outr lado, depois da criação do INEF, em 1940, nada se fez digno de registo no capítulo do ensino, a nível

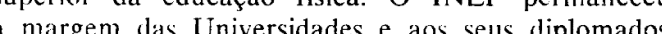
a margem das Universidades e aos seus diplomado

Estés são, por certo, indices seguros do abandono a que foi volada pelo fascismo a educaçao fisica do povo portugues, com

Este é, pois, um dos campos onde, praticamente tudo está por fazer. Aceitando que o bacharelato assegura um nivel de preparação suficiente para docência da Educação Física, atribui-se aos dois Inj. titutos Superiores de Educação Física agora criados a missão de conceder, além do grau de licenciado até do grau de doutor, o grau de bacharel. Assim s justifica a extinção das escolas de instrutores de educacão fisica.

0 artigo 3 - do decreto identifica que as instalações e equipamento do Instituto Nacional de Educação Física e da Escola de Instrutores de Educação Física de Lisboa e do da Escola de Instrutores do Porto, bem como os direitos e obrigações de sua titularidade, transferem-se com dispensa de qualquer formalidade, para a Universidade Técnica de Lisboa no primeiro caso e para a Universidade do Porto no segundo caso. Estava ainda previsto no referido diploma a atribuição dos graus de bacharel e licenciado (arto 6) e doutoramento (arto 9), organizarem departamentos (arto 10) bem como a transição do corpo docente e não docente do INEF e das Escolas de Instrutores de Educação Física para os Institutos Superiores de Educação Física do Porto e Lisboa (arto 14 e 15). 0 arto 18 previa a preparação das eleições dos órgãos de gestão dos Institutos Superiores de Educação Física de Lisboa e Porto através da Comissão Instaladora criada pelo despacho do Ministro de Educação e Cultura de 2 de Outubro de 1974, cessando as suas funções logo após a posse destes membros eleitos. Os diplomados pelos Cursos de Instrutores de Educação Física eram equiparados a bacharéis para efeitos de provimento de lugares da carreira docente nos ensinos básico e secundário e médio e para efeitos de prosseguimento de estudos, desde que tivessem 3 anos de bom e efetivo serviço em Educação Física (arto21). É também abolida a subordinação dos diplomados com o curso de Instrutores de Educação Física à orientação dos professores com o curso do Instituto nacional de Educação Física de acordo com o Decreto-Lei no 49233 de 11 de Setembro de 1969 (art²5), passando-se a intitular como professores (artํ24). Aos alunos titulares com o curso do Instituto Nacional de Educação Física era atribuído o grau de licenciado (arto 27 ) desde que tivessem 3 anos de bom e efetivo serviço.

A IMPLEMENTAÇÃO DOS INSTITUTOS SUPERIORES DE EDUCAÇÃO FÍSICA

O 1ํㅡㄴ Concurso de assistentes para o ISEF de Lisboa e Porto é aberto em Janeiro de 1976 e logo em seguida são realizadas eleições democráticas para os primeiros órgãos de gestão dos dois institutos. Estes dois acontecimentos marcam definitivamente a entrada da educação Física na Universidade.

Nos anos de 1976, 1977 e 1978, são realizados os cursos de profissionalização de bacharéis em Lisboa e no Porto destinados a diplomados pelas Escolas de Instrutores de educação Física que consistiam numa série de módulos de formação e na realização de um estágio pedagógico e apresentação de um relatório. Este trabalho (em que também colaborei ativamente) foi muito exigente, mas permitiu harmonizar a formação de profissionais de Educação Física e Desporto em Portugal. Mais tarde, os Institutos de Educação Física de Lisboa e Porto abriram cursos especialmente dedicados a estes bacharéis através dos famosos Planos Especiais de Licenciatura. Deste modo, foi possível fomentar uma grande coerência ao grau académico em Educação Física e Desporto Nacional.

O ISEF de Lisboa, por Despacho Normativo do Ministro da Educação de 18 de agosto de 1989, passou a ser designado por Faculdade de Motricidade Humana e integrada na Universidade Técnica de Lisboa e o ISEF do Porto, com a publicação do Despacho Normativo n. $.73 / 89$, de 4 de agosto, passou a designar-se Faculdade de Ciências do Desporto e Educação Física, integrada na Universidade do Porto, tendo em 2005 alterada a designacão para Faculdade de Desporto de acordo com a revisão de estatutos da Universidade do Porto. Deve dizer-se que a publicação da lei da autonomia das universidades veio dar um contributo assinalável nas mudanças introduzidas em ambas as faculdades, melhorando consideravelmente o nível de iniciativas e estratégias de desenvolvimento. Ambas as instituições conseguiram de acordo com as suas singularidades históricas, alcançar a credibilidade e o respeito no meio universitário e na comunidade científica ao nível nacional e internacional, contribuindo de forma decisiva para o desenvolvimento do desporto e da educação física em Portugal, através de uma formação pedagógica e científica mais robusta dos seus profissionais. 


\section{SER E CONSTRUIR A UNIVERSIDADE}

\section{EM EDUCACÃO FÍSICA E DESPORTO}

A entrada da Educação Física e Desporto na Universidade, constituiu um enorme desafio para os Institutos Superiores de Educação Física e Desporto de Lisboa e Porto. 0 início de atividade dos diversos regimes de instalação dos dois institutos apresentou diversas dificuldades até se encontrar uma estabilidade de funcionamento legitimamente formalizado. Tudo estava por fazer para construir a estrutura e o pensamento que pudessem justificar a aquisição do estatuto de universidade. É preciso dizer que era enorme a falta de docentes com formação científica adequada e que o património anterior das escolas de formação se radicava numa cultura estigmatizada em saberes meramente técnicos e pedagógicos na formação em educação física. Antes do 25 de Abril apenas tinha sido criado no INEF no final dos anos sessenta um Gabinete de Estudos de Psicologia Aplicada onde foram elaborados os primeiros estudos de investigação. Neste sentido, foi necessário desenvolver um longo trabalho para dotar os Institutos Superiores de Educação Física com as infraestruturas e os recursos humanos adequados para ser possível um desenvolvimento sustentável de qualidade de formação pedagógica e científica. Saliento alguns aspetos cruciais nesse processo de desenvolvimento:

1. A formação de docentes e a opção pela carreira académica, que constituiu uma primeira rutura que foi possível ultrapassar, e em certos casos uma tomada de decisão muito difícil para colegas com um currículo altamente prestigiado do ponto vista profissional;

2. Ultrapassar a carência de conhecimentos existente em muitas áreas disciplinares através do convite de especialistas internacionais ou em trabalhos de investigação em parceria com universidades estrangeiras;

3. Alterar a dependência existente da cultura francófona e adotar com maior relevo o conhecimento científico disponível existente em língua inglesa;

4. Desenvolver saberes em áreas disciplinares específicas em Educação Física e Desporto (fisiologia do exercício, biomecânica, crescimento e desenvolvimento motor, aprendizagem motora, psicologia e sociologia do desporto, gestão do desporto, pedagogia do desporto, etc.);

5. Implementar a formação académica dos docentes através de provas públicas em mestrados e doutoramentos a fim de assegurar a consolidação do corpo docente e de investigação;

6. Criar áreas departamentais em diversas especialidades através do agrupamento de docentes e investigadores;

7. Criar e dotar os laboratórios em diversas áreas disciplinares com equipamentos científicos adequados a uma mais eficiente formação e investigação de professores e estudantes
8. Estabelecer as condições para uma produção científica de excelência a partir de provas académicas e projetos de investigação financiados ou em parceria nacional e internacional;

9. Criar centros de investigação de forma a reunir linhas de pesquisa estratégica em áreas do saber específicas da educação física e desporto e obter as dotações orçamentais necessárias ao seu financiamento;

10. Promover a formação pedagógica dos docentes de modo a melhorar as competências profissionais dos estudantes;

11. Divurgar o conhecimento produzido pelas instituições em termos internacionais e mobilizar alunos oriundos de diversos países;

12. Promover projetos com a comunidade de acordo com necessidades sociais relevantes

0 trabalho realizado nos últimos 40 anos foi notável. Apesar de ser natural a existência de algumas tensões ou conflitos e diferentes identidades no contexto académico, considero que a nossa autoestima deve ser elevada pela avaliação do trabalho desenvolvido. As gerações mais recentes de docentes no nosso meio académico, deveriam interiorizar com maior humildade o sentido da história e a coerência do processo de desenvolvimento institucional.

A Faculdade de Desporto da Universidade do Porto é hoje uma instituição de referência em todo o mundo. A sua qualidade de ensino nos diversos cursos de graduação e pós-graduação, assim como a qualidade de produção científica marcam esta instituição no contexto nacional e internacional.

\section{TEMPOS DE MUDANÇA}

A área de conhecimento em Educação Física e Desporto é hoje uma especialidade reconhecida no meio académico, social e político. A sua identidade é indiscutível. Vivemos tempos de mudança e será necessário repensar regularmente a missão da universidade e do nosso campo de estudo.

Aprender a mover-se ou aprender a mover o corpo (atividade ou ação motora), é historicamente e ancestralmente a nossa identidade pedagógica, científica e profissional. Aprender a mover o corpo na vida quotidiana e de lazer, no contexto da superação (treino desportivo), no contexto educacional (Educação Física Escolar e Desporto Escolar), no contexto da saúde (exercício e cultura do fitness), no contexto artístico (Dança), no contexto da reabilitação motora (restabelecer atrasos de desenvolvimento motor, emocional, psicológico, emocional e social) é um campo de estudo aliciante mas complexo. 
Aprender a mover o corpo deve pressupor a existência de uma dinâmica evolutiva ou desenvolvimentista e a complexidade de variáveis em presença (genéticas, ambientais e culturais) do nascimento atá à morte. Trata-se de compreender antes de tudo como ocorre o processo de adaptação biológica, psicológica e social ao longo do tempo. Não só a ação motora e lúdica, mas também as perceções, representações, tomadas de decisão e dinâmicas simbólicas que estão associadas ao fenómeno. Aprender a mover o corpo, implica o estudo e observação das dinâmicas de distanciamento (conquista de autonomia) e de proximidade (segurança) no desenvolvimento humano. Aprender a mover o corpo significa adquirir mais confiança, mais bem-estar, mais autoestima e mais superação, independentemente do contexto de ação. Aprender a mover o corpo implica atividade motora e ao mesmo tempo a sua escuta (auto regulação)

Existem entendimentos alternativos de certos conceitos chave das ciências como o poder e a identidade. Cremos ser importante aceitar a coexistência de diferentes interpretações para um mundo que é incerto, complexo e em grande mudança. Só uma conceção de um universalismo pluralista nos permitirá capturar a riqueza das realidades académicas e sociais em que temos vivido e ainda vivemos. Trata-se de um mundo mais instável, um mundo bastante mais complexo, um mundo onde as perturbações desempenham um papel de grande relevo e uma das questões chave é a de como explicar a origem de toda essa complexidade. Diversas ciências deixaram de acreditar que o nível macroscópico pode, em princípio, ser meramente deduzido a partir de um mundo microscópico mais simples. Os sistemas complexos são auto-organizados e que, por consequência, a natureza já não pode ser considerada passiva. Num sistema deste tipo, o futuro é incerto e as condições são irreversíveis. Por isso, as leis que pudermos formular apenas poderão enumerar possibilidades, nunca certezas. 0 conceito de disciplina no ambiente académico é quem tem o verdadeiro poder, preservando o conservadorismo, a vaidade do saber e a convicção falsa da sua demarcação científica e pedagógica. As estruturas disciplinares como que cobriram com um véu protetor, e sempre se mostraram muito relutantes em encorajar qualquer violação das linhas de demarcação. As disciplinas instaladas terão tendência a ignorarem as fronteiras com outras áreas de conhecimento. É preciso libertar o ensino e a investigação da ortodoxia arbitrária. A universidade não pode continuar a pôr-se à margem num mundo em que, uma vez excluída a certeza, a função do académico está necessariamente em vias de mudança e a ideia de cientista neutro é fortemente posta em causa. Hoje em dia, não há clareza nas classificações das ciências. As disciplinas desempenham a função de disciplinar as mentes e de canalizar a energia utilizada na atividade intelectual e de investigação. Necessitamos de revolucionar o modelo de funcionamento da universidade quando temos objetos de estudo com grande complexidade. Precisamos de partir para programas interdisciplinares de formação e pesquisa. É necessário abrir oportunidades efetivas de experimentação criativa dentro do sistema universitário (estruturas de caráter múltiplo, diversificado e descentralizado). Falo de programas integrados de formação e investigação transversais às balizas de demarcação tradicionais, apontados a objetivos intelectuais específicos, e dotados de realismo em função de necessidade de formação profissional e investigação em função de necessidade sociais. Porque não começar por tornar obrigatória a dupla filiação departamental para os professores? 0 que ganharíamos com essa riqueza de reflexão e elaboração de projetos de ação? Acabar com a cultura obsessiva e quase patológica do egocentrismo que se instalou na universidade, pode levar a curto prazo ao desprestígio por emergir capacidades técnicas muito avançadas a par de uma incultura confrangedora de entender a realidade de um mundo em grande mudança.

Tensões e conflitos são necessários para que a diversidade e o pluralismo sejam entendidos como práticas recomendadas de existência do pensamento e ação democrática na Universidade. Como dizia Confúcio: "Não ensines um macaco a trepar às árvores".

Exmo. Senhor Reitor da Universidade do Porto, Exmo. Senhor Diretor da Faculdade de Desporto: a comemoração destes 40 anos de história da integração da Educação Física e Desporto na universidade é um momento de grande significado e simbolismo histórico. E notável o desenvolvimento alcançado por esta instituição de ensino superior universitário instalada desde 1997 neste complexo do Polo II da Universidade do Porto. Não posso deixar de referir os nomes dos Professores Jorge Bento e António Marques entre muitos docentes e trabalhadores não docentes desta Faculdade que contribuíram para este êxito do desenvolvimento da Faculdade de Desporto. Ao consultar o Plano de Atividades de 2011-2015 da Faculdade de Desporto, é possível verificar o dinamismo, a excelência, a competência e o alcance dos objetivos de trabalho desta instituição que alcançou um grande e incontestável prestígio nacional e internacional. Por isso estão todos de parabéns.

Muito obrigado pela vossa atenção.

Porto, 3 de Dezembro de 2015 